\title{
artículos
}

\section{Estudio de los lienzos de la Anunciación conservados en la Sala de la Catedral de Santiago de Compostela}

Paula Pita Galán

Universidad de Santiago de Compostela

PALABRAS CLAVE: Pintura Barroca/ Arquitectura Religiosa/ Santiago de Compostela.

\section{RESUMEN}

En 1998, José María Díaz Fernández, archivero de la catedral de Santiago de Compostela, planteó la posibilidad de que los lienzos de la Anunciación de su Sala Capitular fuesen dos obras realizadas por el maestro italiano Guido Reni. En este artículo, se realiza un estudio pormenorizado de las mismas, relacionándolas con la obra del pintor boloñés. Los resultados cuestionan esta autoría pero revelan parte de la particular historia de cada una de estas telas.

\section{ABSTRACT}

In 1998, José Maria Díaz Fernández, archivist of Saint James of Compostela's Cathedral, posed the possibility that the paintings of the Annuntiation on the Chapter Room were two works made by the italian master Guido Reni. In this paper, it is made a detailed study of these canvas in relation to the works of the bolonian painter. The results question this authority but reveal a part of the particular history of each painting.

En 1992 Leopoldo Fernández Gasalla escribió un artículo acerca del legado artístico del arzobispo compostelano don Pedro Carrillo de Acuña ${ }^{2}$. En él llamaba la atención acerca de la existencia de cuatro lienzos de Guido Reni, propiedad de dicho prelado, que fueron legados, dos de ellos a la catedral de Burgos y los dos restantes

* PITA GALÁN, Paula: "Estudio de los lienzos de la Anunciación conservados en la Sala Capitular de la Catedral de Santiago de Compostela", Boletín de Arte $\mathrm{n}^{\circ} 28$, Departamento de Historia del Arte, Universidad de Málaga, 2007, págs. 83-103.

${ }^{1}$ Este artículo es el resultado de un T.A.D. (Trabajo Académicamente Dirigido) realizado entre los años 2004 y 2005 bajo la dirección del profesor de la Universidad de Santiago de Compostela Miguel Taín Guzmán. La investigación pudo ser llevada a cabo gracias a una beca Erasmus concedida por dicha Universidad, trabajando en las ciudades de Roma y Bolonia con la ayuda de historiadores y profesionales del arte italianos. entre ellos querría expresar mi especial agradecimiento a la profesora de la Universidad de Roma I Sapienza, Maisa Dalai Emiliani, a Paolo Caucci von Sauken, coccionista privado, y al especialista en Sapienza, Merisa Dexpre Emil mi a Paocio

2 FERNÁNDEZ GASALLA, L.: "Las obras de Guido Reni en la colección del arzobispo de Santiago Don Pedro Carrillo (1656- 1667)", Seminario de Estudios de Arte y Arqueología, Universidad de Valladolid, 1992 págs.430- 435. 
a sus sobrinos ${ }^{3}$. La posibilidad de que cuatro cuadros del maestro boloñés adornasen en su momento el palacio arzobispal de Santiago de Compostela, suscitó las sospechas de que Carrillo pudiese haber dejado algún lienzo de Reni a esta sede, donde hizo erigir su capilla funeraria. En 1997 el canónigo archivero de la catedral, José María Díaz Fernández, conocedor del citado artículo, reparó en dos lienzos conservados en el Museo Catedralicio: un San Gabriel y una Virgen, presentados juntos formando una Anunciación [1 y 2]. La imagen que llamó su atención fue la del ángel anunciante, que presenta un gran parecido con el Arcángel de la última Anunciación pintada por Guido, conservada en la Pinacoteca Cívica de Ascoli Piceno [3]. Así lo señaló en un trabajo publicado en El Correo Gallego donde propone un origen común para ambos cuadros, que procederían de una misma tela que, por su presumible mal estado de conservación, y en época no reciente, habria sido fragmentada, resultando las obras que hoy se pueden contemplar en el museo. Para resaltar su procedencia común, se habría realizado una "chapucera complementación, además de la demarcación ovalada en la misma tela", expresión con que el autor se refiere a los óvalos pintados que enmarcan las figuras, y a posibles añadidos que afectarían a la mano del Ángel y al lirio que sostiene, así como a las manos, cuello y manto de la Virgen. Todas estas reflexiones de Díaz Fernández le llevan a plantear dos grandes preguntas: ¿podría haber un lienzo de Reni tras estas transformaciones? y ¿habría sido este cuadro propiedad de Carrillo de Acuña? ${ }^{4}$. El principal problema que presenta el estudio de estas obras es que, aquello que debería ser lo más inmediato, la reconstrucción de la historia de estos lienzos en la Catedral de Santiago, ha resultado imposible. Carecemos de documentos que puedan dar una pista sobre el momento y circunstancias en que han llegado a Compostela, y de su ubicación original en el templo. Este problema ha provocado que mi labor se centra-

3 'Yten declaro que, en consecuencia del afecto a la Santa Iglesia Metropolitana de Burgos, donde fui Arcediano de Birbiesca (sic), deseando corresponder al cariño que debo a su llustre Cavildo, con mi corto posible he procurado manifestarlo y donado a la dicha Iglesia el cuerpo de Santo de San Lucio mártir en su urna de cristales con su auténtica, y dos quadros grandes para la sala capitular: el uno El Triunfo de David y el otro La Escultura y La Pintura, ambos de Guido con cornisas doradas (...)

el otro La Escultura y La Pintura, ambos de Guido con cornisas doradas (...)
Yten mando a Don Diego Carrillo de Acuña, mi sobrino, caballero del ábito de Alcántara y señor de la casa de mis padres, de los Carrillos de la villa de Tordomar, un quadro de San Juan Desnudo en el Desierto, de medio cuerpo, que es de Guido, y una lámina de San Pedro quando pescaba. Y seis reposteros con mis armas, fábrica de Salamanca, lo menores que tengo. $Y$ una cama de granadillo, con colgadura y sobrecama de gasilla, de Italia (...)

Yten mando a Don Diego Carrillo de Varaona, mi sobrino, Arcediano de Nendos en la Santa y Apostólica Iglesia de Santiago y actualmente collegial del Collegio Mayor de Santa Cruz de Valladolid del Gran Cardenal de España (...) la cama mayor y mejor que tengo de granadillo, guarnecida de bronce dorado, que tiene la cabezera quatro altos, y una Nuestra Señora por remate con su colgadura de bayeta colorada y un quadro de Santa Catalina, que es de Guido. Y otro quadro del Ángel de la Guarda y los ocho reposteros mayores que los tengo con mis armas, fábrica de Salamanca (...)". Extraído de: FERNÁNDEZ GASALLA, L.: Op. Cit., págs. $432-434$.

4 DÍAZ FERNÁNDEZ, J.M.: “¿Una Anunciación de Reni en la Catedral de Santiago?,”en El Correo Gallego, sábado 19 de julio de 1997, pág. 18 


\section{Q artículos Estudio de los lienzos de la Anunciación conservados...}
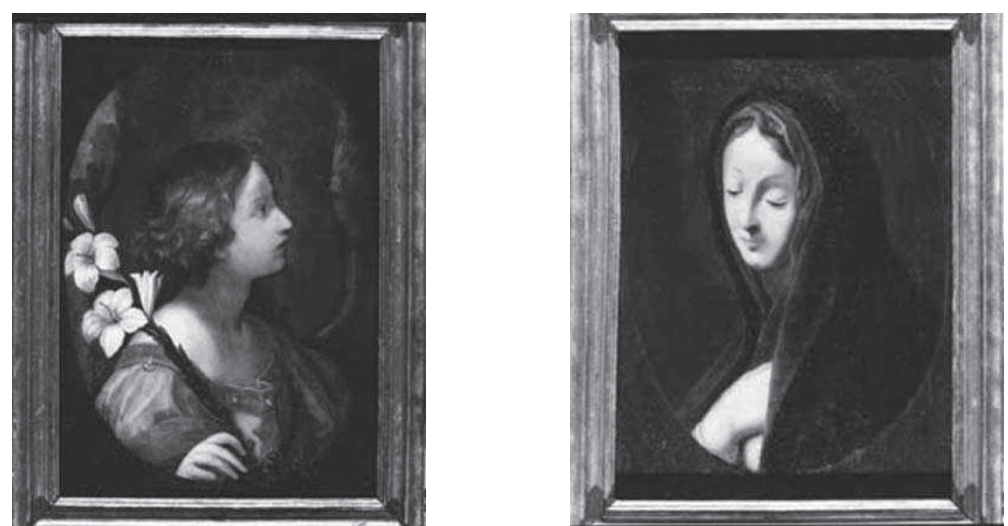

1. Arcángel San Gabriel, Museo Catedralicio de Santiago de Compostela.

2. Virgen de la Anunciación, Museo Catedralicio de Santiago de Compostela.

se en un estudio fundamentalmente formalista, comparando los lienzos compostelanos con las cuatro Anunciaciones que el boloñés realizó a lo largo de su carrera, y complementándolo con el análisis de su pintura, su vida y su modo de trabajo.

\section{Las anunciaciones de Guido Reni.}

Buena parte de la pintura de Guido Reni la componen obras de asunto religioso5; lienzos donde podemos aproximarnos al verdadero sentir del pintor y comprender hasta qué punto era importante en su producción el clasicismo idealista. Pocos artistas han sabido conjugar arte clasicista con temática religiosa como ha hecho Guido. En sus obras vemos cómo, llevando al extremo su afán por el idealismo, logró "divinizar" las formas y rozar una perfección que alcanza lo supraterrenal.

Creados en un ambiente postrentiniano, sus lienzos rezuman un sentimiento

5 Sobre Guido Reni consúltese BELLORI, G.P.: Vite di Guido Reni, Andrea Sacchi e Carlo Maratti,Roma, Biblioteca d'Arte, $4^{a}$ ed. CAVALLI, G.C.: Mostra di Guido Reni, Bologna, Alfa, 1954; GNUDI, C. CAVALLI, G.C.: Guido Reni, Vallecchi, Firenze, 1955; GARBOLI, C., BACCHESCHI, R.: L'opera completa di Guido G.C.: Guido Reni, Vallecchi, Firenze, 1955; GARBOLl, C., BACCHES- 1575- 1642, Los Angeles County Museum
Reni, Rizzoli Editore, Milano, 1971; GRANDARA, C.: Guido Reni: Reni, Rizzoli Editore, Milano, 1971; GRANDARA, C.: Guido Reni: 1575- 1642, Los Angeles County Museum
of Art, Bologna, Nuova Alfa, 1988; MALVASÍA, C.C.: La Felsina pittrice. Vite di pittori bolognesi, Bolonia, 1678; PEPPER, S.: Guido Reni. A complete catalogue of his works whit an introductory text, Oxfors, Phaidon, 1984; SALVY, G. J.: Reni, Electa, Milano, 2001. 


2: artículos Paula Pita Galán

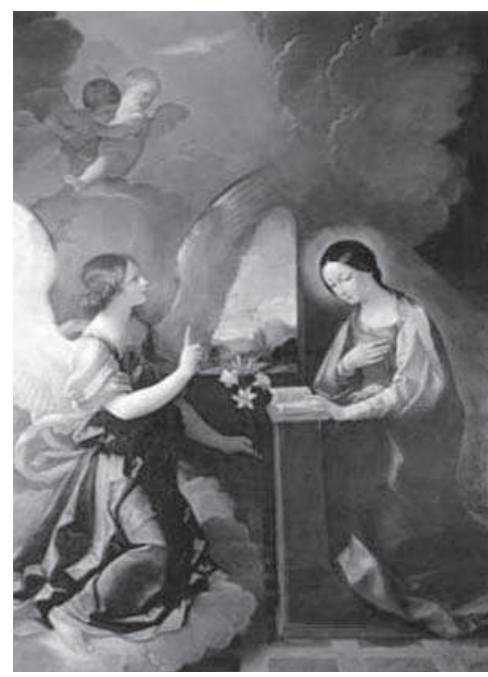

3. GUIDO RENI, Anunciación, Pinacoteca Cívica de Ascoli Piceno. religioso intenso y triunfante, que se reviste de formas ideales, creando unas figuras que, bajo una belleza all'antica, encierran un alma cristiana. Hombre de costumbres religiosas, Reni siempre aspiró a ser el mensajero de la fe a través de una austeridad, casi puritana, que diese autonomía estética a su obra religiosa. Sin embargo, y a pesar de estas pretensiones, no siempre logró desprenderse de la sensualidad amanerada que imprimía a sus imágenes, cayendo a menudo en una excesiva carga melodramática que disminuye la intensidad de la escena. Estas características las encontramos en las cuatro versiones que el boloñés realizó del tema de la Anunciación: la Anunciación de la capilla del Palacio del Quirinal en Roma (1609- 1611), la Anunciación de la iglesia de San Pietro in Valle en Fano, Italia, (1620-1621), la Anunciación conservada en el Museo del Louvre (1627-1632) y la Anunciación de la Pinacoteca Civica de Ascoli Piceno (1634). Las principales diferencias entre estas cuatro obras son de estilo, y están condicionadas por el tipo de encargo. Aquellas realizadas para grandes comitentes, presentan un carácter cortesano y resultan más elaboradas y ostentosas que las dos pintadas para templos provincianos, donde el artista realmente desvela su modo de sentir este pasaje.

La primera de las anunciaciones ocupa el altar de la Cappella dell'Annunciazione, en el Palacio del Quirinal, [4] y fue un encargo del pontífice Pablo IV. Se trata de una representación sencilla, todavía de su etapa de juventud, pero cargada de sentimiento. En ella, el elemento naturalista y la austeridad, heredados de su maestro Ludovico Carracci, desaparecen para imprimir una dignidad a las figuras acorde con la importancia del espacio para el que está destinada la obra. El artista abandona los interiores cotidianos de su maestro, para crear un espacio indefinido, dando preferencia a la representación de la intervención divina -tan del gusto contrarreformista- en el rompimiento de Gloria. La grandilocuencia de esta imagen, se repite en su tercera anunciación, pintada para María de Médicis [5]. En este lienzo, Reni sitúa la escena en un interior sencillo pero con detalles refinados, como el 


\section{Q E artículos Estudio de los lienzos de la Anunciación conservados...}
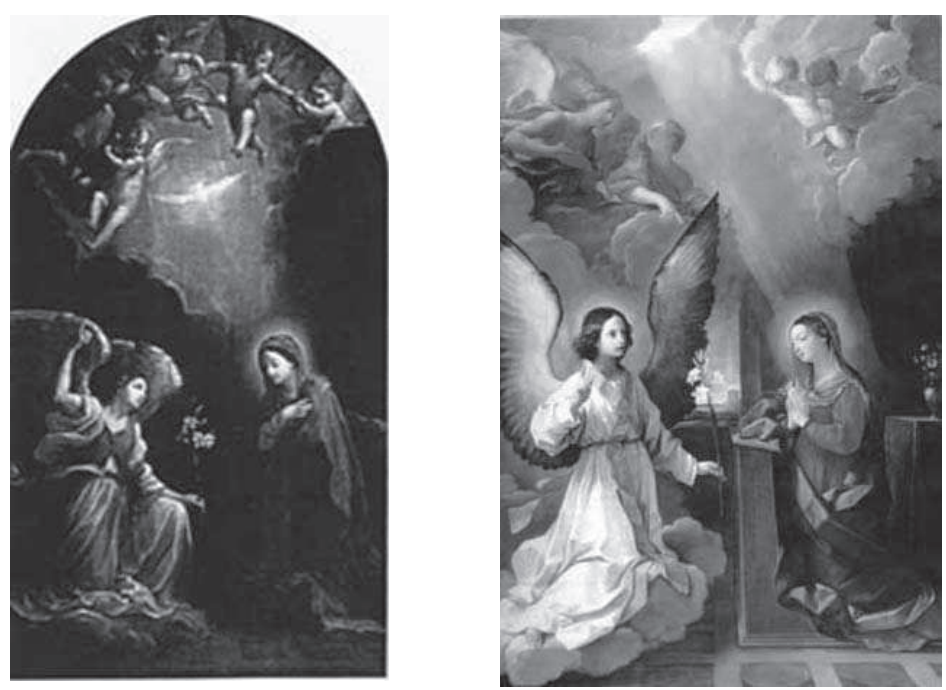

4. GUIDO RENI, Anunciación, Palacio del Quirinal, Roma.

5. GUIDO RENI, Anunciación, Museo del Louvre.

jarrón con flores tras la imagen de María, y abierto al exterior mediante un vano a través del cual se puede ver un paisaje. Frente a la primera Anunciación, obra de un pintor todavía joven que está buscando su estilo, la Anunciación del Louvre responde al hacer de un Guido plenamente formado, que domina a la perfección su oficio y sabe adaptar los modos pictóricos a sus encargos. Son varios los elementos repetidos respecto a la Anunciación del Quirinal, pero ahora logra sacar todo el partido a los mismos, consiguiendo una obra equilibrada y a la vez llena de referencias. La principal diferencia de esta Anunciación, frente a las restantes, es la presencia monumental de María, convertida en protagonista absoluta de la acción. Su imagen es más elegante, acorde con el ambiente palatino en que sitúa la escena, y el grado de sofisticación que alcanza es muy superior al de las otras representaciones. Asimismo, varía el modo de representar a San Gabriel, ahora más aniñado, cuyo rostro anticipa al Arcángel de Ascoli.

Las anunciaciones destinadas a templos presentan un carácter más pío y cercano al pueblo, que sustituye el carácter oficial de las anteriores. En su segunda Anunciación, realizada para la iglesia de San Pietro in Valle de Fano [6], la escena 


Q: artículos Paula Pita Galán

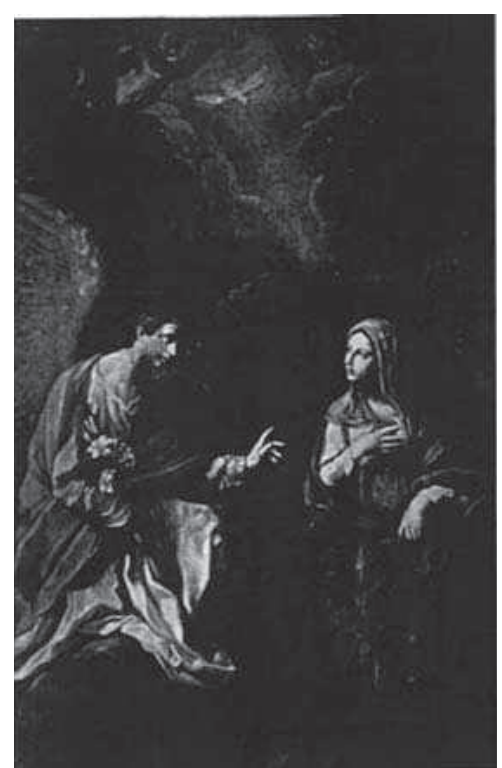

6. GUIDO RENI, Anunciación, Iglesia de San Pietro in Valle, Fano. se representa de nuevo en un interior, pero ahora la intervención divina es menos elocuente.

En este tipo de encargos el pintor está menos sometido a los caprichos del comitente, permitiéndose un discurso más libre y sincero. El resultado son imágenes más humanas y frescas que se relacionan entre sí a través del diálogo mudo de sus miradas. En ninguna anunciación como en la de Fano, el discurso será tan directo, sin embargo esta sensación de vida sí se conserva en la tela de Ascoli. La última Anunciación de Guido [3] fue realizada para la capilla de doña Eleonora Alvitreti, en la Iglesia de la Caridad de Ascoli Piceno. Pasó a ser propiedad del Ayuntamiento ascolano en 1862, y hoy en día se puede contemplar en su Pinacoteca Cívica. Como hemos comentado anteriormente, la imagen del Ángel presenta un gran parecido con el lienzo de Santiago. A pesar de que la delicadeza y factura de la obra de Reni son mayores que la de éste, comparto la opinión de Díaz Fernández a la hora de señalar el lienzo del boloñés como fuente de inspiración para el Ángel compostelano. Con todo, las carnaciones, las sombras, más coherentes y luminosas, y el modo de trabajar las calidades, denotan la superioridad técnica de Guido frente al autor del cuadro del Museo Catedralicio.

La imagen de María, representada como una Virgen-niña, con la cabeza descubierta y enorme sencillez, no se corresponde, sin embargo, con la iconografía de la figura compostelana, por lo que no parece que la efigie mariana de este lienzo pudiera haber servido como modelo para la imagen santiaguesa. Revisando el inventario de las Colecciones Reales del Museo del Prado, descubrí que el precedente iconográfico del lienzo de Santiago no se encuentra en Reni, sino en una obra de otro pintor italiano que trabajaría algunas décadas más tarde que el maestro boloñés: Carlo Maratta6. 


\section{- artículos Estudio de los lienzos de la Anunciación conservados...}

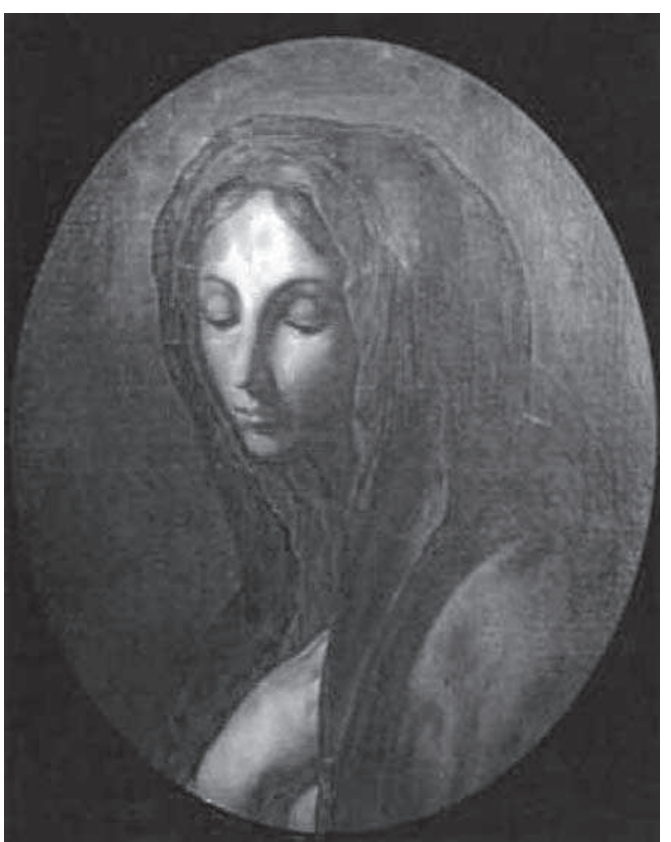

7. Virgen en contemplación, Museo Provincial de Málaga.

El lienzo compostelano es una copia fiel, aunque muy imperfecta, de la Virgen en contemplación [7] que hoy se encuentra en depósito en el Museo Provincial de Málaga, y que está considerada copia de un original de Maratta. La existencia de tal antecedente, descarta de forma definitiva la autoría reniana.

El distinto origen de los lienzos, apuntado por sus diferentes modelos iconográficos, es secundado por el estudio detenido de las telas, que pone de manifiesto una diferente trama, distintos tipos de pigmentos para los tonos marrones y azules, y una evidente disparidad de factura.

Todos estos datos, me llevaron afrontar un estudio por separado de ambas obras, que abordaré a continuación.

${ }^{6}$ AA.VV.: Museo del Prado. Inventario general de pinturas. Tomo I. La Colección Real. Museo del Prado. Espasa Calpe. Madrid, 1990, pág. 661. 
Estudio de la imagen del Arcángel San Gabriel.

Si a simple vista es fácil establecer el parecido entre el Arcángel compostelano y el de Ascoli Piceno, un estudio comparativo de ambos pone de manifiesto que sus diferencias, tanto técnicas como iconográficas, son todavía mayores. Analizando primero las disparidades de tipo técnico, lo más inmediato es el distinto tratamiento de la pincelada, amarrada en la obra del maestro, deshecha y rápida en el lienzo de Santiago. Buena parte de la obra de Reni se caracteriza por este tipo de trabajo minucioso, conocido como "prima maniera", que abandonó únicamente al final de su carrera, por un trazo veloz y aparentemente descuidado denominado "seconda maniera". Ni la primera ni la segunda se asemejan a la técnica empleada en el cuadro del Museo Catedralicio, cuya particularidad es el distinto tratamiento que reciben sus partes. Si comparamos la delicadeza de los cabellos del Ángel, la cenefa de la túnica o el broche, con la tosquedad del manto azul y las alas, no podemos sino pensar en la presencia de, al menos, dos manos ejecutoras, una de ellas considerablemente virtuosa.

Junto a las disparidades técnicas se encuentran las iconográficas. Mientras el referente ascolano responde a la iconografía tradicional del Ángel anunciante ${ }^{7}$, en el cuadro de Santiago la flor de lis es asida con la mano derecha y, debido a la acotación de la obra, desaparece el gesto oratorio típico. Este lirio, que Reni acostumbra a posicionar de forma muy vertical, en el lienzo compostelano se representa en una posición diagonal, puesto que de no ser así, ocultaría el rostro del protagonista. También es significativamente distinto el modo de representar las alas. En el original reniano éstas son blanquecinas, confundiéndose con las nubes, y se despliegan en un pronunciado ángulo obtuso. En la obra del Museo Catedralicio las alas son de un tono parduzco, presentan una factura más dura y se disponen formando un ángulo agudo, ajustándose al contorno del óvalo. Las vestimentas de ambos personajes son otro punto de distanciamiento entre ambas obras. El Arcángel ascolano viste una túnica verde y una blusa de manga abullonada en color ocre. La túnica se prende en el hombro con un tirante ricamente ornado y en el pecho un riquísimo broche con un rubí en el centro sujeta dos cintas color rosáceo. El San Gabriel santiagués, por su parte, lleva una túnica en rosa rematada por una cenefa de oro con pequeñas perlas. Del pecho cuelga un medallón o broche, con una rica montura en oro y una piedra oscura en el centro, y sobre sus hombros cae un manto azul. La diferencia en los vestidos de ambos ángeles es considerable, aunque creo que pretendida por parte

7 Sosteniendo el lirio, símbolo de la pureza y virginidad de María, con la mano izquierda, a la vez que extiende la derecha hacia la Virgen en gesto oratorio: alzando el dedo índice para subrayar sus palabras. Vid. REAU, L.: Iconografía del arte cristiano. Iconografía de la Biblia/ Nuevo Testamento. Volumen 2, tomo 1. Ediciones Serval, Barcelona, 1996, pág. 191. 
del autor del cuadro compostelano. De este modo, evita caer en la copia directa de la obra de Guido, pese a que este lienzo sea su fuente de inspiración, tal y como se desprende de la semejanza de los rostros, la coincidencia lumínica, y detalles como el broche.

Las diferencias iconográficas de la tela compostelana vienen condicionadas, en buena medida, por la presencia del óvalo. Su empleo, era muy común entre las obras del Seicento italiano, siendo una de las tipologías predominantes en las colecciones privadas, sobre todo por su uso en los retratos. En principio no sería de extrañar que dos cuadros de procedencia italiana presentasen este enmarque, e incluso López Ferreiro, en el capítulo de su Historia de la Santa A.M. Iglesia de Santiago de Compostela dedicado al arzobispo Carrillo, habla de dos lienzos con esta misma solución que el prelado donó a su llegada a la sede compostelana. ${ }^{8}$ Asimismo, muchos de los óvalos que hoy vemos en algunos lienzos no fueron realizados para ser vistos, sino que estarían tapados por las molduras de los marcos. La diferencia entre aquellos que no debían ser vistos y los que sí, reside en que, mientras unos están realizados de manera descuidada, los otros presentan un mayor celo en su realización. No parece probable que la tela del Arcángel tuviese en su origen una moldura muy compleja, por lo que parece más plausible pensar que el óvalo que luce hoy en día sea un añadido, tal y como sugiere Díaz Fernández, realizado con el ánimo de crear una forzada relación de complementariedad con el lienzo de la Virgen, que repite fielmente la solución adoptada en el modelo malagueño, del que hablaremos más adelante. Pero, ¿cómo justificar éste y otros posibles retoques?

Durante una estancia en Italia, tuve la posibilidad de ver y fotografiar dos lienzos, copia de la Anunciación de Ascoli, propiedad de Paolo Caucci [8 y 9], ${ }^{9}$ El análisis comparativo del Arcángel de Caucci y el de Santiago, corrobora que, a pesar de las diferencias ya señaladas, ambos parten de un mismo modelo iconográfico, reforzándose así la hipótesis de Díaz Fernández sobre la fuente del lienzo compostelano. No obstante, al confrontar ambas obras lo que realmente me interesaba era tratar de averiguar los posibles pasos que se habían llevado a cabo para llegar al lienzo del Museo Catedralicio. Como todo apunta a que el óvalo no formaba parte de la obra original, probé a incluir por ordenador otro similar en la copia ascolana. El resultado obtenido fue muy interesante [10]. Al aplicar el óvalo, la mano y el ala derecha, la única representada, desaparecen parcialmente, perdiéndose las referencias que permiten identificar con facilidad a este personaje con el ángel anunciante. Este

8 "Está puesto en el altar de Cabildo. It. Dos quadros, el uno de óbalo con marco dorado en que está pintada Nuestra Señora y su Smo. Hijo dormido y el otro de S. Pedro que ambos están colgados en dicha sala",

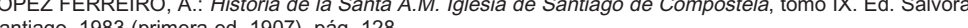
. 128 .

9 Paolo Caucci es director del Instituto de Estudios Jacobeos de la Universidad de Perugia. 


2: artículos Paula Pita Galán
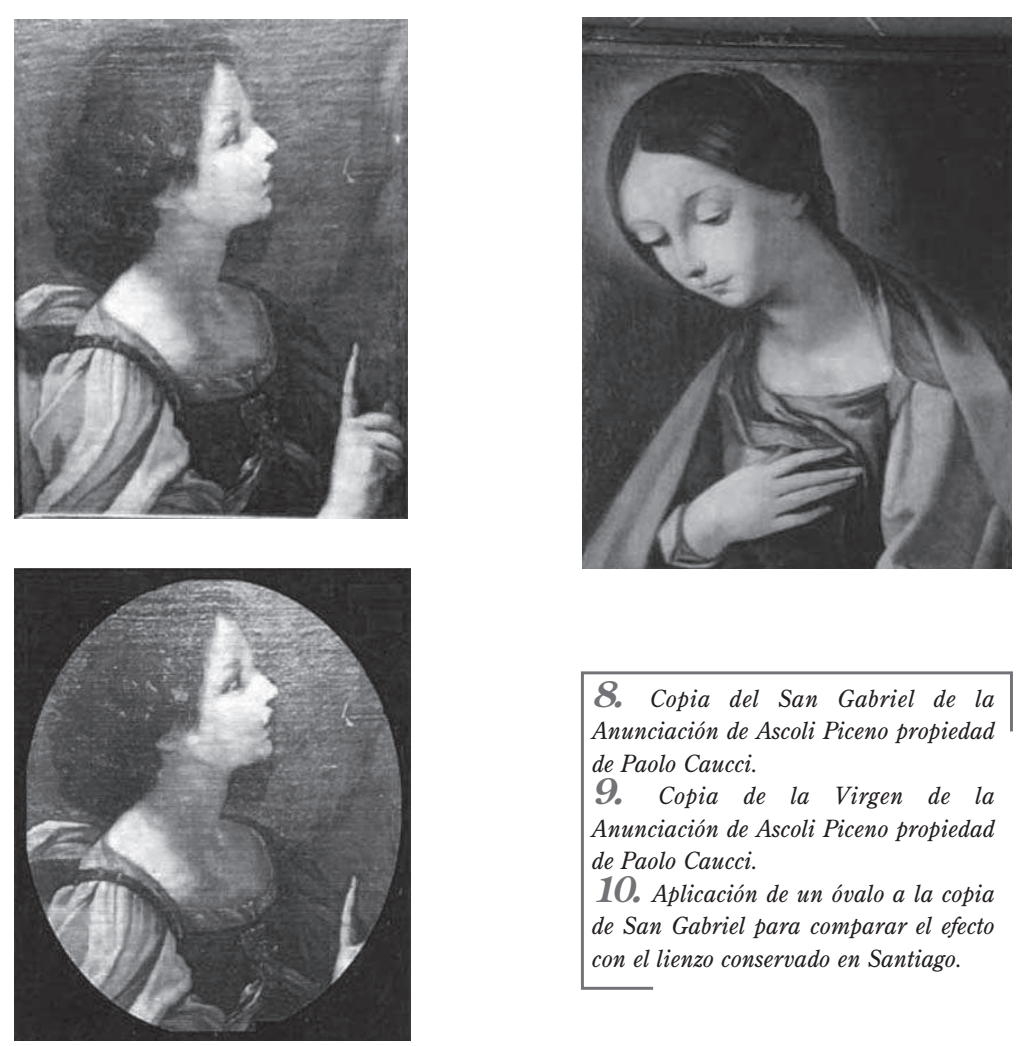

8. Copia del San Gabriel de la Anunciación de Ascoli Piceno propiedad de Paolo Cancci.

9. Copia de la Virgen de la Anunciación de Ascoli Piceno propiedad de Paolo Caucci.

10. Aplicación de un óvalo a la copia de San Gabriel para comparar el efecto con el lienzo conservado en Santiago.

hecho haría necesarios los añadidos que parece presentar el lienzo de Santiago. Así, las alas permiten identificar al Ángel como tal, el lirio se emplea como atributo fundamental de San Gabriel, la mano aparece para que la flor no parezca surgir de ninguna parte $y$, posiblemente, el manto azul se realizaría para tapar una parte de la mano derecha original, que no desaparecería bajo el óvalo. Para dar mayor coherencia al manto que cubre el hombro izquierdo, se pintaría también sobre la mano derecha, disimulando la falta de correspondencia con el brazo y el hombro diestros.

Según el propio Paolo Caucci, copias como las de su propiedad eran muy frecuentes en Ascoli, donde la Anunciación de Reni es una de sus obras más sobresalientes. Ésta es una posible vía para explicar la presencia de un lienzo de estas características en Santiago de Compostela. Ascoli Piceno es una pequeña ciudad 
Q E a tículos Estudio de los lienzos de la Anunciación conservados...

situada en la provincia ascolana, punto de encuentro entre la región de las Marcas, el Lazio, Abruzzo, el Adriático y el territorio de Macerata. Diócesis destacada y próxima a Roma, es posible que sufriese una importante influencia de la capital y recibiese la visita de viajeros curiosos que se habían acercado hasta la Ciudad Santa. Sin embargo, ésta no es la única posibilidad de procedencia para el Ángel compostelano, sobre todo si tenemos en cuenta que también se conserva una copia de taller del lienzo ascolano en la iglesia de San Giovanni in Monte de Bolonia, realizada por Ercole de María, uno de los principales alumnos de Reni10.

De María entró en el taller de vie delle Pescherie como discípulo de Francesco Gessi, y allí se convirtió en uno de los más fieles seguidores de Guido. Carente de autonomía creativa, fue uno de los principales divulgadores de los modelos del maestro, y es conocido como el alumno copista por excelencia. La copia de la Anunciación de Ascoli es un buen ejemplo de su labor en esta escuela. Se trata de un lienzo correcto y fiel en detalles, pero falto de la intensidad del original. La Anunciación de San Giovanni in Monte era la única del maestro en la ciudad, por lo que no pudo dejar indiferente a la población boloñesa. Este templo está situado en el centro de la localidad, en las proximidades de la zona universitaria y junto a la vieja cárcel, por lo que era una de las iglesias más conocidas y frecuentadas de Bolonia. Además, como referente de la pintura religiosa de Reni, no debió de pasar desapercibida a sus conciudadanos ${ }^{11}$. Si a esto unimos la presencia del Colegio Español en Bolonia, se podría plantear que el lienzo de Santiago tuviese un origen boloñés y no ascolano, puesto que esta institución facilitaba los intercambios culturales entre la región emiliana y nuestro país.

Igualmente, hemos de tener en cuenta que en el siglo XVII la copia era muy frecuente, y se entendía de manera muy distinta a como lo hacemos hoy en día. En esta época, la copia del maestro era un instrumento de conocimiento que formaba parte de la formación de cualquier artista, y podía ser una interpretación del original, un homenaje al maestro por parte de un discípulo, o un detalle agrandado de una obra pública. El propio Reni en sus años de formación, tanto en el taller de Calvaert

\footnotetext{
10 PIRONDINI, M., NEGRO, E.: La Scuola di Guido Reni. Banco San Geminiano e San Prospero. Artiol Editore, 1992, págs. 203- 204.

11 Era frecuente que cada vez que el maestro realizaba un encargo importante para fuera de Bolonia se pintase una copia de taller de calidad que era la que quedaba en la ciudad. Asimismo miembros de las familias nobles de la ciudad trataban de adquirir reproducciones de estas obras, algunas de las cuales han llegado hasta nosotros, creando los, hasta nosotros, creando los, lamentablemente demasiado comunes, problemas de atribución. Un ejemplo de ello lo encontramos en la obra Baco y Ariadna (cuyo original, realizado para Cesare Rinaldi se encuentra hoy en Los Angeles County Museum of Art) de la que Malvasía registra cuatro copias: una en la colecció Zambeccari de Bolonia (conservada en Villa Albani y realizada por Gessi), otra en Vigna Peretti, la tercera propiedad de Hipólito Boncampagni y la última perteneciente a Davia, que según Pepper es una copia salida de alguna colección. PEPPER, S.: "Bacchus and Ariadne in the Los Angeles County Museum: the "Scherzo" as artistic mode". The Burlington Magazine, n 959, CXXV (1983), pág. 68 y 71.
} 
como en la Academia de los Carracci, habría realizado numerosas copias de los grandes maestros, algunas contemporáneas a sus primeras obras autógrafas ${ }^{12}$. Cosa muy distinta era la imitación de estilo, vista como una falta de originalidad y duramente condenada en la época. En la actualidad, el problema que plantea la identificación de las obras de Guido, es consecuencia directa de la difusión de esta práctica y del éxito que el pintor tuvo, en su época. Hoy sabemos que, durante el siglo XVII, el margen de seguridad de los peritos en el reconocimiento de las obras de los pintores emilianos, y en concreto los boloñeses, era altísimo y demostrable en numerosas ocasiones. Ejemplo de ello son los numerosos matices con que señalaban las diferencias respecto a las obras de los grandes maestros - "que viene de", "extraídos", "fornidos", "forzados" o "retocados"-, o el hecho de que para las copias de las obras de Reni a menudo es citado el autor o los autores, llegando a diferenciarse distintas manos en un mismo lienzo13. Sólo a finales del XVII, con los últimos y más difusos ecos renianos, la identificación se hace más difícil y la información se vuelve más confusa. Los cuadros más famosos de Reni eran copiados aún en vida del pintor, no sólo en Italia, sino en toda Europa, por lo que a finales de siglo aparecían obras con su estilo en los lugares más diversos. Además, una práctica muy común entre los mecenas boloñeses era la de encargar copias de sus cuadros más prestigiosos para así llamar la atención sobre sí mismos y su colección.

Anteriormente, señalaba que el Ángel del Museo Catedralicio no es una copia fiel de la imagen de Ascoli sino que presenta ciertas diferencias en el rostro y en detalles como la vestimenta, que me hacen pensar en una contaminación de estilos. Es muy posible que se tratase de una obra "inspirada en" la pintura de Guido, pero realizada a partir de unos modelos iconográficos que no se encuentran tanto en las obras del propio pintor como en las de sus discípulos, reforzándose así el posible origen boloñés del lienzo. Los parecidos más razonables se encuentran en los rostros de algunas figuras de Francesco Gessi, uno de los alumnos destacados del taller ${ }^{14}$. La obra de este pintor se caracteriza por dar a sus figuras un perfil picudo, acentuado por el dibujo de la nariz y, sobre todo, por el carnoso labio superior, que da a sus imágenes un aspecto muy particular. Este tipo de perfil lo hallamos en la Sacra Famiglia con

\footnotetext{
12 Ejemplo de ello es la Santa Cecilia que hoy se puede contemplar en una capilla de la nave derecha de la iglesia de San Luis de los Franceses en Roma, copia a menor escala del original de Rafael de la Pinacoteca Nazionale di Bologna.

13 SALVY, G.: Op. Cit., pág. 30.

14 El parecido entre las obras de Gessi y el Ángel de Santiago me lo apuntó Nicossetta Roio, historiadora que trabaja en el Istituto della Graffica de Bolonia, y colaboradora en el libro La Scuola di Guido Reni, a la cual estoy muy agradecida. Asimismo Roio resaltó que este tipo de perfil no se encuentra en la pintura de ningún otro discípulo del maestro boloñés.

Sobre el taller de Reni consultar: PIRONDINI, M, NEGRO, E.: Op. Cit. pág. 327 y 328; MALVASÍA, C. C.: Op. Cit., págs. 549- 554
} 


\section{- E atúculos Estio de los lienzos de la Anunciación conservados...}

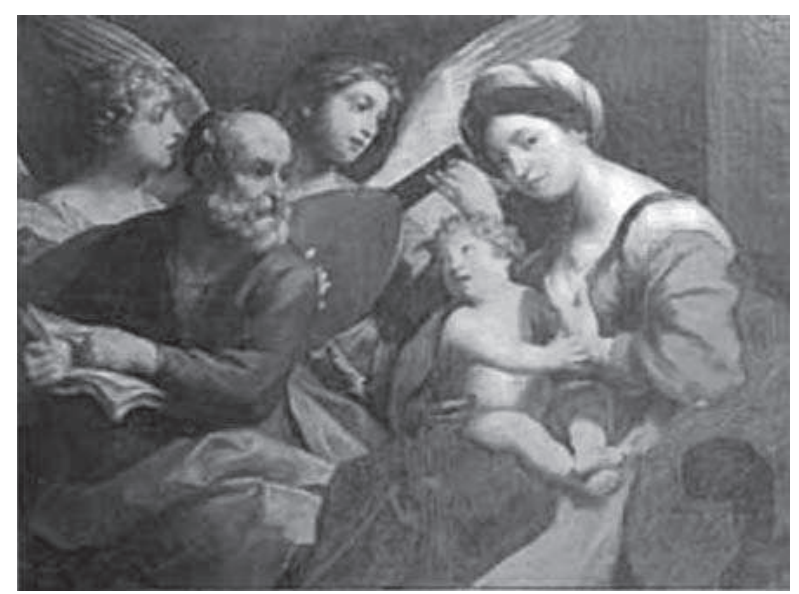

11. FRANCESCO GESSI, Sacra Famiglia con angeli musicanti, Pinacoteca Nazionale, Bolonia.

angeli musicanti de la Pinacoteca de Bolonia [11], en el ángel de la izquierda, y en la Alegoría de la Pintura [12] propiedad de la Caja de Ahorros de Bolonia. A pesar del parecido, la pintura amarrada, claroscurista y en la que predominan las tonalidades verdosas, propia de Gessi, poco tiene que ver con las característica generales de nuestro lienzo; estas obras únicamente recalcan la idea de que el origen del Arcángel está más próximo al ambiente pictórico de Bolonia que al de Ascoli Piceno.

El Encuentro de Rebeca y Eliecer [13] conservado en la Pinacoteca del florentino Palacio Pitti, de Giovanni Andrea Sirani, otro alumno destacado, refuerza nuestra hipótesis ${ }^{15}$. En este lienzo, de nuevo, he encontrado una figura con un perfil muy semejante al del Ángel compostelano. Al igual que sucede con el artista anterior, tampoco considero que el lienzo del Museo Catedralicio pertenezca a Sirani, que aunque trabaja con una pincelada más deshecha, semejante a la del cuadro santiagués, tiene un mayor dominio del oficio que su autor.

Estas semejanzas y diferencias entre los alumnos de Guido y el lienzo del Museo Catedralicio me hacen pensar en la existencia de un diseño de taller, -el mismo empleado para crear la imagen del ángel Gabriel de la Anunciación de Ascoli-

\footnotetext{
15 Sobre Giovanni Andrea Sirani ver PIRONDINI, M., NEGRO, E.: Op. Cit., pág. 365 y 367.
} 


2: artículos Paula Pita Galán
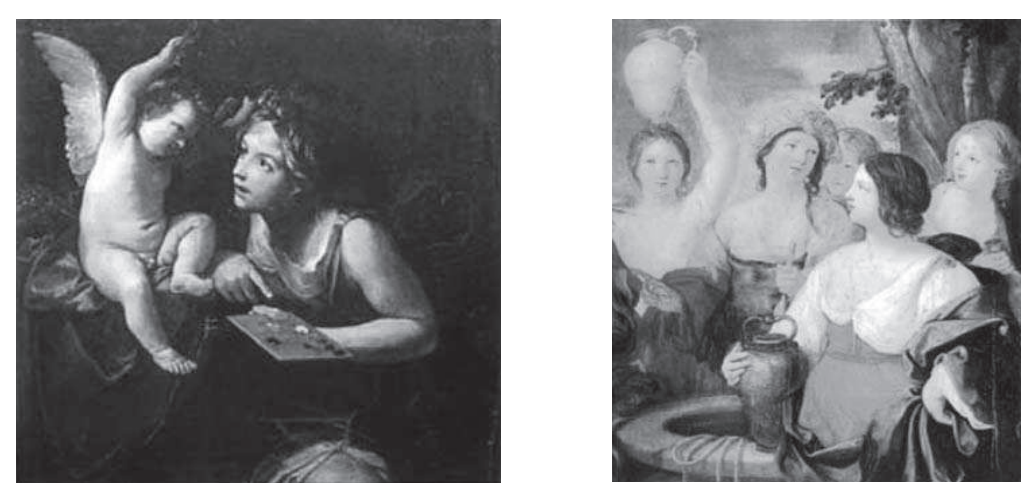

12. FRANCESCo GeSSI, Alegoría de la Pintura, Caja de Ahorros de Bolonia.

13. GIOVANNI ANDREa SIRANI, Encuentro de Rebeca y Eliécer (detalle), Pinacoteca del Palacio Pitti, Florencia.

conocido por los discípulos de Reni, que lo habrían hecho propio, reinterpretándolo y adaptándolo en sus obras. Tanto Gessi como Sirani abrieron importantes talleres y gozaron de gran popularidad en Bolonia, convirtiéndose en referentes de su vida artística. Sus obras eran tan conocidas como las de su maestro, y sus alumnos igualmente numerosos, lo que contribuyó en buena manera a la difusión de los diseños de Guido, pero contaminados por las características de estos artistas. De este modo la transmisión de modelos habría llegado hasta el siglo XVIII, fecha a partir de la cual, según Andrea Emiliani -director de la Pinacoteca Nacional de Bolonia y principal autoridad en pintura boloñesa-, habría sido realizado el Ángel de Santiago ${ }^{16}$.

\section{Estudio de la imagen de la Virgen Compostelana.}

El cuadro que representa a la Virgen de la Anunciación [2] es el de peor calidad en esta pretendida pareja de lienzos. El afilado perfil y sus duras facciones la apartan del estilo boloñés, caracterizado por las mujeres de grandes rostros ovalados, de extrema dulzura y delicadeza. Los tonos fríos y las carnaciones blanquecinas, carentes de matices, contrastan con la imagen del Ángel y con la iconografía típica de esta Virgen, representada como una mujer joven, de rostro sonrosado y con

16 El profesor Emiliani tuvo la amabilidad de estudiar las fotografías de los lienzos de Santiago, emitiendo el citado juicio. 
2: artículos Estudio de los lienzos de la Anunciación conservados...

expresión de infantil inocencia - tal y como las caracteriza Reni en sus lienzos ${ }^{17}$. La potente luz, cuyo foco procede de la izquierda, hace desaparecer el modelado sutil, de suaves traspasos lumínicos, que veíamos en el rostro del arcángel, provocando que la efigie de María, resulte opaca e insípida, además de falta de volumen y de toda vida, alejándose de la gracia que le debe ser propia. El velo, realizado a base de toscas veladuras, carece de transparencia, confundiéndose con los cabellos castaños, mientras el manto, burdo y pesado, cae sin gracia alejándose de los amplios y majestuosos pliegues de las telas renianas.

Iconográficamente esta imagen, que aparece cubierta por un pesado manto, no se corresponde con la representación de una Annunziata, asemejándose a la imagen propia de una Virgen en contemplación de su hijo muerto. La presencia de esta prenda, unida a la extraña postura de las manos, llevó a Díaz Fernández a pensar de nuevo en la presencia de retoques. Sin embargo, revisando el Inventario de las Colecciones Reales del Museo del Prado con la intención de conocer las obras de Reni que habían sido propiedad de los monarcas españoles, y por tanto podían ser conocidas en el país, encontré un cuadro catalogado como "Virgen en Contemplación. (Copia de Reni) obra de Carlo Maratta" [4], hoy depositado en el Museo Provincial de Málaga, y que responde al detalle al lienzo de la Museo Catedralicio de Compostela ${ }^{18}$. La existencia de esta obra, apunta a que la conservada en Santiago es una mala copia, posiblemente realizada por algún pintor español. En el lienzo malagueño las facciones de la Virgen, mucho más delicadas, son las propias de una mujer joven. Su rostro, de perfil más ovalado que el de la réplica, responde a los semblantes de las Vírgenes de Maratta, caracterizados por un contorno fino y pómulos prominentes. La iluminación matizada, poco tiene que ver con el potente foco que ilumina a la Virgen compostelana, encontrándonos ahora ante una luz cálida que crea tonalidades doradas en carnaciones y cabellos. El velo carece de transparencia, pero logra ser más sutil que el de la imagen santiaguesa, y el manto, aunque pesado, resulta mucho menos burdo. Pero lo más destacado es que, al contrario que el lienzo del Ángel, que presentaba diferencias iconográficas respecto al original, el cuadro de María es totalmente fiel a la obra malagueña, compartiendo su particular iconografía.

Esta representación anómala revierte en la denominación que se da al lienzo original. En el inventario del Prado se conserva una primera catalogación bajo el título Virgen en Contemplación, que considera la obra una copia de Reni realizada por Carlo Maratta. Por su parte, Pérez Sánchez en Pintura italiana del siglo XVII en España19, la denomina Busto de la Virgen, y descarta que sea copia de una obra de

17 Y tal y como la describe Louis Reau en REAU, L.: Op. Cit. pág. 188.

18 Vid. Nota 6. 


2: artículos Paula Pita Galán

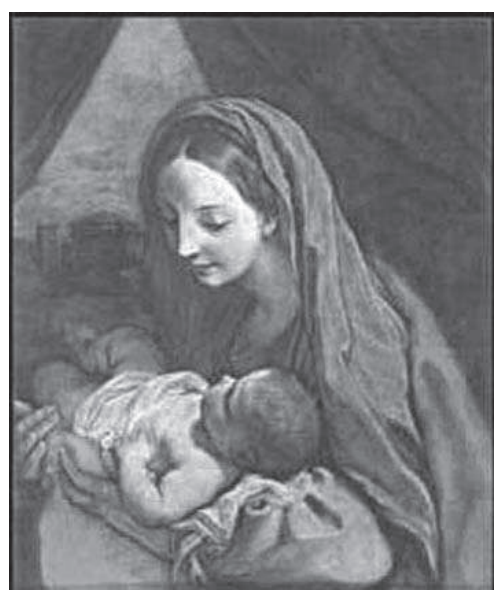

14. CARLO MARATTA, Virgen con el Niño, Kunsthistorisches Museum, Viena.

Guido, por las diferencias de estilo que presenta ${ }^{20}$. Por el contrario, señala el parecido con una Virgen con el Niño del Kunsthistorisches Museum de Viena [14], obra de Maratta, reforzando su autoría. A pesar de que la calidad de este lienzo es muy superior a la del conservado en Málaga, efectivamente la influencia de Carlo Maratta parece más probable que la de Guido Reni. Esta semejanza estilística, está secundada por algunos documentos y el modo en que esta obra llegó a nuestro país. Según la ficha que me facilitó el Museo del Prado21, el lienzo malagueño llegó a España formando parte de la colección de Carlo Maratta, gracias a la mediación de uno de sus principales discípulos: Andrea Procaccini. Este artista fue el escogido por el maestro como depositario de su colección de pinturas y diseños 22 , y por Felipe $\mathrm{V}$ para trabajar como pintor de Cámara y maestro de obras del Palacio de La Granja, entre 1720 y 1734, año de su muerte. El pintor romano llegó a la corte por iniciativa del cardenal Francesco Acquaviva, el 23 de agosto de 1720. Tres días después se presentó ante los reyes, causándoles una gran impresión, tal y como se desprende de su nombramiento como pintor de cámara y sus actividades como consejero artís-

19 PÉREZ SÁNCHEZ, A.E.: Pintura italiana del siglo XVII en España. Madrid, Universidad de Madrid, Fundación Valdecilla. Sucesores de Rivadeneyra, 1965

20 Esta obra que Pérez Sánchez denomina Busto de la Virgen es la Virgen en contemplación del Museo Provincial de Málaga. Vid. PÉREZ SÁNCHEZ, A.E.: Op. Cit., pág. 298.

21 Aprovecho para agradecer a los trabajadores del departamento de cultura del Museo del Prado el haberme facilitado toda la información que poseían acerca de este lienzo, además de una reproducción en color del mismo, que es la que he incluido en el apéndice.

22 Estos últimos conservados en la Real Academia de San Fernando de Madrid. 
Q E atículos $\quad$ Estudio de los lienzos de la Anunciación conservados...

tico 23 . Sus habilidades para este cometido quedan demostradas en el asesoramiento a los monarcas de la adquisición de la colección de obras de su maestro, Carlo Maratta y de la de esculturas de Cristina de Suecia. Cuando, entre finales de 1722 y comienzos de 1723, la hija mayor de Maratta, Faustina, puso a la venta la colección de su padre, Procaccini, que conocía bien la calidad de estos lienzos, propiedad de su maestro, instó a Felipe V a comprar las 123 obras que la integraban 24 . Entre los lienzos citados en el inventario, se incluian cuadros de Rafael, Andrea del Sarto, Giovanni Bellini, Tiziano, Ippolito Scarsella (Scarsellino), Rubens, Poussin, Peter Neefs, así como lienzos del propio Maratta, de los Carracci, Andrea Sacchi, Domenichino y Pier Francesco Mola, lo cual constata la importancia de la colección de este artista, aunque no se cita el lienzo que nos interesa ${ }^{25}$.

Aunque, efectivamente, el lienzo de Málaga presenta rasgos que recuerdan a la pintura de Carlo Maratta, su calidad es inferior a la de las obras del que fue Príncipe de la Academia de San Luca de Roma. En cuanto a la figura de Reni, se puede considerar descartada, aunque su pintura tuviese cierta influencia sobre el pintor romano. En la biografía de Maratta, el teórico Giovan Pietro Bellori, gran literato defensor del arte clásico y amigo del pintor, señala el conocimiento que éste tiene de la obra de Guido, al referirse al fresco que representa la Huida a Egipto en la Capilla de San José, de la Iglesia de San Isidoro en Roma (1652), una obra de juventud encargada por Flavio Alaleone 26 . Hasta cierto punto, es lógico que el primero -que nunca se desplazó más allá de la provincia de Roma- no fuese ajeno a la obra del boloñés, entonces considerado el principal exponente del clasicismo italiano, y con una nutrida cantidad de obras en la ciudad. Allí, Guido trabajó principalmente, para nobles y príncipes de la Iglesia, con los que Maratta pronto entró en contacto. Por su formato ovalado, es probable que el lienzo esté realizado a partir de otro perteneciente a una colección particular, mientras que su iconografía tampoco dista en exceso de la Annunziata del Quirinal de Reni, obra que el pintor romano debió de conocer cuando pintó la Galería del Palacio de Montecavallo. Que el lienzo malagueño no sea el posible original de Maratta se puede justificar si lo comparamos con una copia que este pintor realizó de la Cabeza de Ariadna [15], proceden-

23 BOTTINEAU, YVES: El arte cortesano en la España de Felipe V (1700- 1746), Madrid, Fundación Universitaria Española, 1986, págs. 450 y 451.

24 Ibídem., pág. 475

25 ANES, G.: Las Colecciones Reales y la fundación del Museo del Prado. Fundación de Amigos del Museo del Prado. Ed. El Viso, S.A., Madrid, 1996, pág. 36

26 BELLORI, G.P.: Op. Cit., $4^{a}$ ed., págs. 74- 79. Bellori comenzó una biografía de Maratta que no llegó a concluir, siendo terminada posteriormente por Antonio de Rossi. En su libro el crítico italiano habla una por una de las obras más significativas del príncipe de la Academia romana, siendo el punto de partida fundamental para el estudio de este artista. Con todo, hemos de tener en cuenta la amistad que unía a historiador y pintor, lo que provoca que las consideraciones del primero resulten, en ocasiones, poco objetivas. 


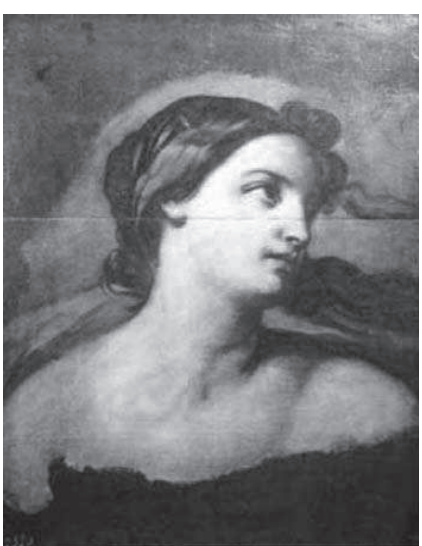

15. Carlo Maratta, Cabeza de Ariadna, Museo Provincial de Málaga. te de Las bodas de Baco y Ariadna de Guido. Esta copia, también depositada en el Museo Provincial de Málaga, pertenece claramente a un pintor de calidad muy superior al autor de la Virgen. En cualquier caso, se trate de una obra de Maratta o una copia de un seguidor suyo, parece que la Virgen en contemplación fue una obra que tuvo cierta divulgación entre los siglos XVIII y XIX tal y como constata la existencia de la copia compostelana.

\section{Conclusiones.}

La idea inicial de este estudio, era analizar si, efectivamente, cabía la posibilidad de que el Museo Catedralicio de Santiago contase con dos lienzos de Guido Reni. Tras analizar la obra del pintor, el ambiente en que vivió y su modo de trabajar, parece improbable que las obras en cuestión fuesen realizadas por el maestro boloñés. Las diferencias técnicas entre las telas compostelanas y las obras de Guido son claras, tanto con las de la "prima maniera", como con las de la "seconda". A pesar de no estar relacionados técnicamente, hemos podido comprobar que, como señaló Díaz Fernández, el lienzo que representa a San Gabriel tienen un claro parentesco iconográfico con el Arcángel de la Anunciación que el boloñés pintó para la iglesia de la Caridad de Ascoli Piceno. La Virgen, sin embargo, no goza de las características de la escuela boloñesa. El hallazgo de su precedente iconográfico en una copia de Carlo Maratta, y las comentadas diferencias técnicas, la desligan de su pareja en el museo compostelano, descartando la hipótesis de que ambos lienzos fuesen fragmentos de una obra mayor, y constatando, a su vez, la presencia de, al menos, dos maestros distintos: el del Ángel, más diestro, y el de la Virgen.

Antes de localizar este referente, el análisis de la pintura de Guido, y en concreto de sus Anunciaciones, me llevó a descartar que el San Gabriel compostelano fuese de su realización, pero, conociendo su sistema de trabajo, consideré oportuno estudiar la obra de los miembros más destacados de su Escuela. De este modo, encontré parecidos razonables entre la imagen santiaguesa y las obras de Francesco Gessi y Giovanni Andrea Sirani, pero también pude comprobar que el dominio técnico de ambos artistas era superior al del autor de este lienzo, opinión 
que fue respaldada por historiadores especializados en pintura boloñesa. La posibilidad de que fuera Sirani el autor de la obra, la descartó Maricetta Parlatore, encargada de realizar la reciente restauración de un lienzo del pintor y de su hija Isabella. Su postura fue secundada por Andrea Emiliani, que también desechó la posibilidad de que fuese obra de Gessi. Para el director de la Pinacoteca Nacional de Bolonia, la imagen del Ángel fue realizada en el siglo XVIII, por lo que no podría ser obra de Reni, fallecido en 1642, ni de sus más directos seguidores.

En cualquier caso, sí queda claro que el precedente del San Gabriel se encuentra en el Arcángel de la Anunciación de Ascoli Piceno, aunque parece más acertado considerar el lienzo una interpretación, probablemente de la copia de taller conservada en la iglesia de San Giovanni in Monte de Bolonia. A la hora de plantear esta hipótesis, he tenido en cuenta los parecidos que el lienzo de Santiago presenta respecto a las obras de otros pintores boloñeses y, sobre todo, la existencia del Colegio Español de Bolonia, institución que contaba con una importante presencia en la ciudad. Es posible que el lienzo de San Gabriel no llegase sólo a Compostela, sino acompañado por una imagen de María, en un grupo semejante al de Paolo Caucci. La pérdida del cuadro de la Virgen podría haber provocado que se encargarse una copia de otro lienzo mariano, o que se forzase la complementariedad del Ángel con algún lienzo perteneciente a los fondos de la Catedral. De este modo se produjo su unión con la copia de la Virgen en Contemplación, tal y como los vemos hoy en día. Para articular visualmente esta pareja de lienzos, se pudieron llevar a cabo los citados añadidos que presenta la imagen de San Gabriel, comenzando por el óvalo y siguiendo por las alas, la mano y el lirio. Al principio era un tanto reticente a considerar todos estos elementos como retoques, pero, al comprobar los efectos del óvalo sobre una imagen semejante, descubrí que suponía la desaparición de aquellos referentes que lo dotaban de una identidad concreta, obligando a realizar las citadas modificaciones. Por otro lado, el hecho de que el lienzo de María sea una copia de otro cuadro, descarta definitivamente la posibilidad de que ambos procedieran de una tela mayor. Para evitar errores al respecto, revisé ambas obras con la ayuda de Ana Abella, restauradora de la Universidad de Santiago. El estudio de los lienzos bajo luz natural deja ver con claridad cómo el tipo de pigmento varía del cuadro del Arcángel al de la Virgen, siendo especialmente notable la diferencia de las tonalidades azules y los marrones de los óvalos. Esta diferencia apoya la idea, ya expresada, de que el óvalo del San Gabriel pudiera tratarse de un repinte, a la vez que descarta que los cuadros procedan de un mismo taller. Asimismo, al contemplar el reverso de ambos lienzos se hace patente la diferencia de las telas, demostrándose que estas obras nunca tuvieron un origen común.

Si la datación propuesta por Emiliani para el lienzo del Arcángel -comienzos del XVIII, como fecha más temprana- es correcta, hemos de descartar definitivamen- 
te la figura del arzobispo Carrillo de Acuña como introductor de los lienzos en la ciudad de Santiago, puesto que el prelado falleció en Compostela en el año 1677. A pesar de que en su testamento se citan los lienzos de Reni, y de la argumentación de Fernández Gasalla, el prelado distaba bastante de los grandes coleccionistas y mecenas que debió de conocer durante su estancia en Roma, entre 1633 y 1643, donde fue auditor de la Rota ${ }^{27}$. Como señala Folgar de la Calle, es evidente que el ferviente ambiente artístico que Carrillo se encontró en la ciudad italiana lo impresionó profundamente, y ejemplo de ello es la Capilla del Santo Cristo de Burgos, que el prelado hizo erigir en la catedral compostelana para su enterramiento, tomando como ejemplo la Capilla Paolina de la iglesia romana de Santa María la Mayor ${ }^{28}$. Sin embargo, el eclecticismo que denota el legado a sus sobrinos, demuestra que Carrillo carecía del gusto y de los conocimientos propios de un gran comitente "all" italiana", dejándose atraer por objetos de diversa índole y cuadros de un pintor "de moda"29. Esto mismo me hace sospechar que, posiblemente, los cuadros de Reni, que con tanto orgullo se citan en su testamento, no fuesen sino copias de algunos de los que, por entonces, se encontraban en las colecciones privadas romanas.

Sí podemos aproximar, sin embargo, la fecha de realización de la imagen de la Virgen. El lienzo en que se inspira esta obra, llegó a España el año 1723, con lo cual contamos con un término ante quem, que nos lleva a movernos dentro del siglo XVIII. Asimismo, he encontrado un término post quem que me permite ajustar algo más la datación de esta obra. En el retablo dedicado a María, de la sacristía de San Martín Pinario, trazado por fray Plácido Caamiña entre las dos últimas décadas del XVIII, aparece una copia, en menores dimensiones, del lienzo de la Virgen del Museo Catedralicio. Teniendo en cuenta estos datos, todo apunta a que el lienzo debió de llegar a Santiago durante el segundo tercio de este siglo. La existencia de esta reproducción, nos señala que el cuadro de María debió de causar cierta impresión en el ámbito compostelano, hasta el punto de que fue reproducido en obras contemporáneas de menor entidad.

Las relaciones entre España e Italia han sido constantes entre los siglos XVII y XIX, e intenso fue, también, el interés de los monarcas españoles por el arte italiano. Muchos lienzos y pintores italianos llegaron a España gracias a la monarquía, nobles y órdenes religiosas. Este arte llegaba fundamentalmente a Madrid y, desde la capital, se difundía a las regiones periféricas. Sevilla, Valladolid, Salamanca,

27 MANUEL R. PAZOS, O.F.M: Episcopado gallego, Tomo I: Arzobispos de Santiago (1550- 1850), Madrid, Consejo Superior de Investigaciones Científicas. Instituto Jerónimo Zurita, 1946, págs. 182 y 183.

28 FOLGAR DE LA CALLE, Ma C.: Capilla del Cristo de Burgos de la Catedral de Santiago. Obras maestras restauradas, Madrid, Fundación Argentaria, 1998, pág. 21.

29 FERNÁNDEZ GASALLA, L.: Op.Cit., págs. 432- 433. 
Q artículos Estudio de los lienzos de la Anunciación conservados...

Valencia o Toledo, fueron algunos de los puntos de recepción de estos artistas y de sus epígonos. El interés por el arte italiano y especialmente por la pintura, llevaría a la realización de copias de los lienzos de los pintores más destacados, que circularían por todo el país, causando una gran expectación, en ciudades de provincias faltas de una fuerte tradición pictórica, como Santiago de Compostela. 
